\title{
28 Research Suare \\ Combination of Violet Light Irradiation and Collagenase Treatments in a Rabbit Model of Keratoconus
}

Hidenaga Kobashi ( $\nabla$ himon@hotmail.co.jp)

Keio University https://orcid.org/0000-0002-0767-4214

Takashi Yano

Life Science Liboratories

Kazuo Tsubota

Keio University: Keio Gijuku Daigaku

\section{Research Article}

Keywords: violet light (VL), Keratoconus

Posted Date: December 21st, 2021

DOI: https://doi.org/10.21203/rs.3.rs-1106934/v1

License: (c) (i) This work is licensed under a Creative Commons Attribution 4.0 International License.

Read Full License 


\section{Abstract}

Purpose: We evaluated the use of collagenase treatment to generate a rabbit model of keratoconus and the impact of violet light (VL) irradiation on the disease model in six Japanese White rabbits.

Methods: After epithelial debridement, the collagenase group was treated with a collagenase type II solution for $30 \mathrm{~min}$; the control group was treated with a solution without collagenase. Three rabbits also underwent VL irradiation ( $375 \mathrm{~nm}$, irradiance $310 \mu \mathrm{W} / \mathrm{cm}^{2}$ ) for 3 hours daily for 7 days after topical collagenase application. Slit-lamp microscopy results, steep keratometry (Ks), corneal astigmatism, central corneal thickness, and axial length were examined before and after the procedure. The corneas were obtained on day 7 for biomechanical evaluation.

Results: A significant increase in Ks and corneal astigmatism was observed in the collagenase and VL irradiation groups compared with the control group at day 7. No significant difference was found in the change in corneal thickness between the groups. The elastic modulus at $10 \%$ strain, but not at $3 \%$ and $5 \%$ strain, was significantly lower in the collagenase group than in the control group. There was no significant difference in the elastic modulus at each level of strain between the collagenase and VL irradiation groups. The average axial length at day 7 was significantly longer in the collagenase group than in the control group. Collagenase treatment induced a keratoconic model by steepening the keratometric and astigmatic values. There was no significant difference in the observed elastic behaviour of normal and ectatic corneas under physiologically relevant stress levels.

Conclusion: VL irradiation did not cause regression of corneal steepening in collagenase-induced model during short-term observation.

\section{Introduction}

Keratoconus $(\mathrm{KC})$ is a progressive, frequently asymmetric, corneal thinning disorder characterized by changes in the structure and organization of corneal collagen $[1,2]$. It results in corneal thinning and protrusion, progressive myopia, and irregular astigmatism. It is difficult to establish an ex vivo and in vivo corneal ectatic model of KC. Previous studies have examined treatment of corneal ectasia using excimer lasers, but the cornea shape did not result in a KC model [3, 4]. Hong et al. reported a significant increase in corneal curvature in human donor corneas after topical collagenase application [5]. Qiao et al. mimicked KC with increased corneal keratometry, corneal thinning and a lower elastic modulus using rabbits [6]. Wang et al. developed an ex vivo corneal ectatic model that mimics $\mathrm{KC}$ by applying collagenase and chondroitinase enzymes to rabbit corneas [7]. However, other parameters, such as corneal astigmatism and axial length, have not been investigated. Ihalainen et al. reported increased collagenase and gelatinase activities in the medium of human $\mathrm{KC}$ corneal cultures [8]. The lack of animal preclinical models of $\mathrm{KC}$ has been an obstacle for evaluating potential new therapies. Because abnormal collagenase activity and decreased total collagen levels are present in KC, exposure of collagenous enzymes to normal tissue may be able to simulate some aspects of acute KC disease. 
Recently, we reported a novel technology, KeraVio, consisting of violet light (VL) irradiation and riboflavin treatment, in rabbit and human corneas [9]. KeraVio halted disease progression in eyes with corneal ectasia, similar to corneal cross-linking (CXL). KeraVio treatment uses an eyeglass with a $375 \mathrm{~nm}$ wavelength VL source applied to the cornea, and the patients wear the eyeglass daily without limitations. Corneal epithelial peeling in CXL not only induces ocular pain after surgery but also carries a potential risk of corneal infection. KeraVio treatment avoids these complications of CXL surgery and may become another option for KC treatment, but its efficacy has not been compared with that of CXL. To simplify the treatment procedure, we preliminarily identified originally endogenous riboflavin in the human cornea without adding riboflavin drops, and a relatively low intensity of VL irradiation itself strengthened the corneal stiffness in porcine corneas (data not shown). Subsequently, a clinical trial of KeraVio without riboflavin drops was launched (jRCTs032190267). We evaluated the impact of topical collagenase on eyes treated with KeraVio without riboflavin drops, but the corneal biometry needs to be clarified.

The aim of this study was to evaluate corneal biometry after treatment with both collagenase and VL irradiation in rabbit eyes.

\section{Methods}

Nine female Japanese White rabbits weighing 1.5-2.0 kg were used in the study. All animals were healthy and free of ocular disease. In six rabbits, the right eyes were treated with collagenase type II, and the left eyes were treated as the control group ( $n=6$ in each group). In the other three rabbits, KeraVio treatment was applied to both eyes after topical collagenase application $(n=6)$. All animals were treated according to the Association for Research in Vision and Ophthalmology Statement for the Use of Animals in Ophthalmic and Vision Research.

A topical anaesthetic consisting of $0.4 \%$ oxybuprocaine hydrochloride was applied to the eyes. After epithelial debridement, corneal trephines were placed on the corneas. In the collagenase group, a 10 $\mathrm{mg} / \mathrm{mL}$ collagenase type II solution (Worthington, Lakewood, $\mathrm{NJ}$ ) in balanced salt solution and $15 \%$ dextran was applied to the surface of the corneas with corneal trephines. The solution was then removed with cotton swabs, and the corneas were rinsed with $0.9 \%$ sodium chloride solution. The control eyes were subjected to the same protocol but without collagenase type II in the applied solution. The KeraVio process began with the application of collagenase in the same manner as in the collagenase group. VL irradiation $(375 \mathrm{~nm}$ ) was applied using a single VL diode (Nitride Semiconductors Co., Ltd., Tokushima, Japan) with an irradiance of $0.31 \mathrm{~mW} / \mathrm{cm}^{2}$ for 180 minutes at a distance of $60 \mathrm{~cm}$ from the cornea (total energy dose $3.3 \mathrm{~J} / \mathrm{cm}^{2}$ ). KeraVio treatment using only VL irradiation was continued for 7 days (total energy dose $23.4 \mathrm{~J} / \mathrm{cm}^{2}$ ).

Before surgery, the rabbit eyes were subjected to slit-lamp examinations to identify evidence of conjunctival injection, corneal infiltration and corneal stromal inflammation. These examinations were repeated every day during the 7-day study to assess ocular safety; an examination was carried out before collagenase treatment and repeated every day during the 7-day study. Corneal keratometry and the 
central corneal thickness (CCT) were recorded at baseline (the day before treatment) and 7 days after treatment using a handheld keratometer (Retinomax 3; Righton, Tokyo, Japan) and an ultrasound pachymeter (SP-100; Tomey, Nagoya, Japan), respectively, under topical anaesthesia. Three measurements were taken at each time point, and the mean value of each parameter was recorded along with the change in its value. The mean steep keratometry (Ks), corneal astigmatism, CCT and changes in each parameter were evaluated. The axial length was also recorded at 7 days after treatment using a digital calliper.

The rabbits were euthanized with an intravenous overdose of sodium pentobarbital on day 7 . The corneas were harvested en bloc along the sclera. A 2- to 3-mm scleral rim was preserved, and the cornea was attached along a custom-made scale. Then, a 5-mm wide corneal strip was resected vertically along the cornea. The corneal strips were clamped vertically at a distance of $5 \mathrm{~mm}$ between the jaws. The CCT at day 7 in each cornea was used to calculate the cross-sectional area of the corneal strip. After the prepared corneal strip was placed on a computer-controlled electronic universal testing machine (TA, XTplusC Texture Analyser ${ }^{\mathrm{TM}}$, Stable Micro Systems, Ltd., London, UK), a fixture was applied to hold the corneoscleral limbus of the corneal strip during a uniaxial tensile test. For the actual measurement, the sample was stretched at a velocity of $1.8 \mathrm{~mm} / \mathrm{min}$ up to a maximum force of $5 \mathrm{~N}$. The elastic modulus was defined as the ratio of tensile stress (amount of force causing deformation per unit trans-sectional area of the corneal strip) to tensile strain (percentage change in the length caused by the stress). For the subsequent statistical analysis, the elastic modulus was consistently evaluated at $3 \%, 5 \%$, and $10 \%$ strain.

Analyses were performed with Statistical Analysis Software (version 9.4; SAS Institute, Cary, NC). The outcome measures are reported as the mean \pm standard deviation. A two-tailed paired t-test was used in the statistical analyses to compare the parameters between the two groups. A P value of $<0.05$ was considered statistically significant.

\section{Results}

After collagenase treatment, daily slit-lamp examinations showed no conjunctival injection, corneal infiltration or corneal stromal inflammation throughout the follow-up period. Fluorescein stain examinations showed complete corneal epithelial healing at approximately 7 days after the surgery.

At baseline, the Ks values in the collagenase and KeraVio with collagenase groups did not differ from that in the control group ( $P=0.090$ and $P=0.686$, respectively). Table 1 shows the Ks values from baseline throughout the 1-week observation period. The change in Ks in the collagenase and KeraVio with collagenase groups was significant at day 7 compared with that in the control group (each $P=0.029$ ). 
Table 1

Changes in steep keratometry over time.

\begin{tabular}{|c|c|c|c|c|c|}
\hline & $\begin{array}{l}\text { Baseline } \\
\text { dioptres (D) }\end{array}$ & $\begin{array}{l}1 \text { week } \\
\text { (D) }\end{array}$ & $\begin{array}{l}\text { Change from baseline to } 1 \\
\text { week (D) }\end{array}$ & $\begin{array}{l}* P \\
\text { value }\end{array}$ & $\begin{array}{l}+P \\
\text { value }\end{array}$ \\
\hline Collagenase & $54.73 \pm 0.66$ & $\begin{array}{l}61.81 \pm \\
7.18\end{array}$ & $7.08 \pm 7.62$ & 0.029 & $\mathrm{n} / \mathrm{a}$ \\
\hline $\begin{array}{l}\text { KeraVio with } \\
\text { collagenase }\end{array}$ & $56.46 \pm 3.94$ & $\begin{array}{l}62.59 \pm \\
8.12\end{array}$ & $6.13 \pm 8.01$ & 0.029 & 0.999 \\
\hline Control & $57.62 \pm 2.78$ & $\begin{array}{l}53.06 \pm \\
1.58\end{array}$ & $-4.56 \pm 2.94$ & $\mathrm{n} / \mathrm{a}$ & $\mathrm{n} / \mathrm{a}$ \\
\hline \multicolumn{6}{|c|}{ *Compared with the control group. } \\
\hline \multicolumn{6}{|c|}{ †Comparison between collagenase with and without KeraVio. } \\
\hline \multicolumn{6}{|l|}{$\mathrm{D}=$ dioptres } \\
\hline $\mathrm{n} / \mathrm{a}=$ not $\mathrm{app}$ & & & & & \\
\hline
\end{tabular}

At baseline, the corneal astigmatism in the collagenase and KeraVio with collagenase groups did not differ from that in the control group ( $P=0.447$ and $P=0.164$, respectively). Table 2 demonstrates the corneal astigmatism values from baseline throughout the 1 -week observation period. The changes in corneal astigmatism in the collagenase and KeraVio with collagenase groups were significant at day 7 compared with that in the control group ( $P=0.005$ and 0.004 , respectively).

Table 2

Changes in corneal astigmatism over time.

\begin{tabular}{|c|c|c|c|c|c|}
\hline & $\begin{array}{l}\text { Baseline } \\
\text { (D) }\end{array}$ & $\begin{array}{l}1 \text { week } \\
\text { (D) }\end{array}$ & $\begin{array}{l}\text { Change from baseline to } 1 \\
\text { week (D) }\end{array}$ & $\begin{array}{l}* P \\
\text { value }\end{array}$ & $\begin{array}{l}+P \\
\text { value }\end{array}$ \\
\hline Collagenase & $\begin{array}{l}1.74 \pm \\
1.02\end{array}$ & $\begin{array}{l}20.13 \pm \\
9.95\end{array}$ & $18.38 \pm 10.51$ & 0.005 & $\mathrm{n} / \mathrm{a}$ \\
\hline $\begin{array}{l}\text { KeraVio with } \\
\text { collagenase }\end{array}$ & $\begin{array}{l}5.63 \pm \\
2.83\end{array}$ & $\begin{array}{l}20.50 \pm \\
7.37\end{array}$ & $14.88 \pm 6.06$ & 0.004 & 0.886 \\
\hline Control & $\begin{array}{l}4.03 \pm \\
2.70\end{array}$ & $\begin{array}{l}2.94 \pm \\
1.17\end{array}$ & $-1.10 \pm 3.81$ & $\mathrm{n} / \mathrm{a}$ & $\mathrm{n} / \mathrm{a}$ \\
\hline \multicolumn{6}{|c|}{${ }^{*}$ Compared with the control group. } \\
\hline \multicolumn{6}{|c|}{ tComparison between collagenase with and without KeraVio. } \\
\hline \multicolumn{6}{|l|}{$\mathrm{D}=$ dioptres } \\
\hline $\mathrm{n} / \mathrm{a}=$ not applicable & & & & & \\
\hline
\end{tabular}

At baseline, the CCT in the collagenase and KeraVio with collagenase groups did not differ from that in the control group $(P=0.127$ and $P=0.200$, respectively). Table 3 presents the CCT values from baseline 
throughout the 1-week observation period. The change in CCT in the collagenase and KeraVio with collagenase groups was not significantly different at day 7 compared with that in the control group $(P=$ 0.248 and 0.343 , respectively).

Table 3

Changes in central cornea thickness over time.

\begin{tabular}{|c|c|c|c|c|c|}
\hline & $\begin{array}{l}\text { Baseline } \\
(\mu \mathrm{m})\end{array}$ & 1 week $(\mu \mathrm{m})$ & $\begin{array}{l}\text { Change from baseline to } 1 \\
\text { week }(\mu \mathrm{m})\end{array}$ & $\begin{array}{l}* P \\
\text { value }\end{array}$ & $\begin{array}{l}+P \\
\text { value }\end{array}$ \\
\hline Collagenase & $\begin{array}{l}380.75 \pm \\
39.03\end{array}$ & $\begin{array}{l}320.50 \pm \\
107.77\end{array}$ & $-60.25 \pm 143.06$ & 0.248 & $\mathrm{n} / \mathrm{a}$ \\
\hline $\begin{array}{l}\text { KeraVio with } \\
\text { collagenase }\end{array}$ & $\begin{array}{l}377.50 \pm \\
37.86\end{array}$ & $\begin{array}{l}289.09 \pm \\
148.40\end{array}$ & $-88.50 \pm 173.00$ & 0.343 & 0.686 \\
\hline Control & $\begin{array}{l}341.50 \pm \\
21.11\end{array}$ & $\begin{array}{l}343.50 \pm \\
26.45\end{array}$ & $2.00 \pm 17.26$ & $\mathrm{n} / \mathrm{a}$ & $\mathrm{n} / \mathrm{a}$ \\
\hline \multicolumn{6}{|c|}{ *Compared with the control group. } \\
\hline \multicolumn{6}{|c|}{ tComparison between collagenase with and without KeraVio. } \\
\hline \multicolumn{6}{|c|}{$\mathrm{n} / \mathrm{a}=$ not applicable } \\
\hline
\end{tabular}

Table 4 shows the elastic modulus of the treated corneas at 3\%, 5\%, and $10 \%$ strain. We found significant differences in stress values between the collagenase and control groups at $10 \%$ strain $(P=0.043)$, but the elastic modulus of the treated corneas at $3 \%$ and $5 \%$ strain did not differ between the groups.

Table 4

Comparison of the elastic modulus in each group.

\begin{tabular}{|c|c|c|c|c|c|c|c|c|c|}
\hline & $\begin{array}{l}3 \% \\
(\mathrm{kPa})\end{array}$ & $\begin{array}{l}* P \\
\text { value }\end{array}$ & $\begin{array}{l}+P \\
\text { value }\end{array}$ & $\begin{array}{l}5 \% \\
(\mathrm{kPa})\end{array}$ & $\begin{array}{l}* P \\
\text { value }\end{array}$ & $\begin{array}{l}+P \\
\text { value }\end{array}$ & $\begin{array}{l}10 \% \\
(\mathrm{kPa})\end{array}$ & $\begin{array}{l}* P \\
\text { value }\end{array}$ & $\begin{array}{l}+P \\
\text { value }\end{array}$ \\
\hline Collagenase & $\begin{array}{l}96.69 \pm \\
66.84\end{array}$ & 0.686 & $\mathrm{n} / \mathrm{a}$ & $\begin{array}{l}100.98 \\
\pm 74.87\end{array}$ & 0.486 & $\mathrm{n} / \mathrm{a}$ & $\begin{array}{l}121.77 \\
\pm \\
104.32\end{array}$ & 0.043 & $\mathrm{n} / \mathrm{a}$ \\
\hline $\begin{array}{l}\text { KeraVio with } \\
\text { collagenase }\end{array}$ & $\begin{array}{l}264.34 \\
\pm \\
219.60\end{array}$ & 0.057 & 0.343 & $\begin{array}{l}289.75 \\
\pm \\
275.20\end{array}$ & 0.057 & 0.999 & $\begin{array}{l}466.24 \\
\pm \\
495.68\end{array}$ & 0.668 & 0.343 \\
\hline Control & $\begin{array}{l}354.80 \\
\pm \\
245.43\end{array}$ & $\mathrm{n} / \mathrm{a}$ & $\mathrm{n} / \mathrm{a}$ & $\begin{array}{l}407.89 \\
\pm \\
284.91\end{array}$ & $\mathrm{n} / \mathrm{a}$ & $\mathrm{n} / \mathrm{a}$ & $\begin{array}{l}604.37 \\
\pm \\
361.35\end{array}$ & $\mathrm{n} / \mathrm{a}$ & $\mathrm{n} / \mathrm{a}$ \\
\hline \multicolumn{10}{|c|}{ *Compared with the control group. } \\
\hline \multicolumn{10}{|c|}{ tComparison between collagenase with and without KeraVio. } \\
\hline \multicolumn{10}{|c|}{$\mathrm{n} / \mathrm{a}=$ not applicable } \\
\hline
\end{tabular}


Table 5 demonstrates the average axial length at day 7 . The axial length in the collagenase group was significantly longer than that in the control group $(P=0.021)$. Fig. 1 shows a representative whole collagenase-treated eye, KeraVio-collagenase-treated eye, and control eye after euthanasia.

Table 5

Average axial length at day 7 in each group.

\begin{tabular}{|llll|}
\hline & Axial length at day $7(\mathrm{~mm})$ & $* P$ value & $\boldsymbol{T} P$ value \\
\hline Collagenase & $20.28 \pm 1.52$ & 0.021 & $\mathrm{n} / \mathrm{a}$ \\
\hline KeraVio with collagenase & $19.05 \pm 1.96$ & 0.114 & 0.343 \\
\hline Control & $16.45 \pm 1.58$ & $\mathrm{n} / \mathrm{a}$ & $\mathrm{n} / \mathrm{a}$ \\
\hline *Compared with the control group. & & \\
\hline †Comparison between collagenase with and without KeraVio. & \\
\hline n/a = not applicable & & \\
\hline
\end{tabular}

When we compared each parameter between the collagenase and KeraVio with collagenase groups, there was no significant difference in the change in $\mathrm{Ks}$, corneal astigmatism, CCT, corneal stiffness at $3 \%, 5 \%$, and $10 \%$ strain or axial length.

\section{Discussion}

In the present study, collagenase treatment induced a significant increase in Ks (7.08 dioptres (D)) at day 7, which is consistent with the clinical characteristics of irregular corneal topography. Hong CW et al. reported that collagenase treatment resulted in a significant increase in corneal curvature in human corneas by $6.6 \pm 1.1 \mathrm{D}$ [5]. Wang $\mathrm{X}$ et al. demonstrated that rabbit corneas exposed to collagenase ex vivo showed a significant decrease in CCT [7]. Some studies have also focused on the relationship between corneal keratometry and time. Our study also revealed a similar decrease in Ks in the control group. Although previous studies evaluated keratometry and corneal thickness after collagenase treatments, corneal astigmatism was not clarified $[5,6]$. To imitate $\mathrm{KC}$, we measured corneal astigmatism as a lowerand higher-order aberration. Compared to the control group, the collagenase group exhibited a significant increase in corneal astigmatism (18.38 D) at day 7.

Regarding axial length, we reported previously that VL irradiation may have the potential to retard myopia progression [10]. We assessed the impact of VL irradiation on the change in axial length in eyes treated with collagenase. However, there was no significant difference in the axial length at day 7 between eyes treated with collagenase with and without KeraVio.

We found significant differences in the elastic modulus between the collagenase and control groups at $10 \%$ strain $(P=0.043)$, but the value of the treated corneas at $3 \%$ and $5 \%$ strain did not differ between the groups. When the elastic modulus of corneal strips is generally compared, the value at $10 \%$ strain is 
useful and is commonly recorded $[11,12]$. In our study, the stress-strain curves showed an exponential increase, as in the previous investigation by Wollensak et al. [11]. Thus, values at $3 \%$ and $5 \%$ strain often do not differ between groups. Compared to a relevant report by Qiao et al. [6], our elastic modulus demonstrated high standard deviations in each group. The discrepancy might be attributable to the differences in measurement conditions of the stress-strain test. No obvious inflammatory reactions were observed in the eyes throughout the follow-up, indicating that treatment with collagenase does not result in inflammation.

Regarding the impact of KeraVio with collagenase on the cornea, no significant difference was shown in any parameter between the collagenase and KeraVio with collagenase groups. However, the KeraVio with collagenase group had a slightly higher elastic modulus at $10 \%$ strain than that in the collagenase group. We suggest that this effect may have been due to the higher concentration of collagenase, short-term follow-up, and absence of riboflavin drops in the KeraVio with collagenase group. The short-term followup of 7 days might be a limitation of this study because remodelling in the cornea is unstable. However, the KeraVio treatment provided sufficient VL irradiation for 7 days to produce a total energy dose that was 4.3-fold higher than the dose delivered by the standard Dresden protocol for CXL $\left(23.4 \mathrm{~J} / \mathrm{cm}^{2} \mathrm{vs} .5 .4\right.$ $\mathrm{J} / \mathrm{cm}^{2}$ ). Because the current study did not include corneal changes after the CXL technique, it was difficult to determine whether KeraVio outperformed CXL in terms of preventing corneal changes. We compared the elastic modulus after KeraVio and standard CXL treatments without collagenase application using porcine corneas [13]. The preliminary data indicated similar outcomes between the two treatment groups [13]. To our knowledge, this is the first study to investigate corneal biometry and biomechanics after treatment with collagenase with and without KeraVio.

The main limitation of the current study is that it did not assess the long-term impact of this novel corneal ectasia treatment. This one-week observation may be too short to obtain a comprehensive understanding of this enzymatic degradation model, although in the present study, a significant increase in Ks and significant decreases in the elastic modulus were observed in 1 week. In addition, long-term observation is necessary for further identification of changes in $\mathrm{Ks}$, corneal astigmatism, and tensile strength, which could confirm the sustainability of this novel model. Additional studies with long-term follow-up are warranted to better investigate the reliability and efficacy of this in vivo animal model of corneal ectasia.

In conclusion, a method for generating keratometric features of $\mathrm{KC}$ was demonstrated in rabbit eyes treated with collagenase. There was no significant difference in the observed elastic behaviour of normal and ectatic corneas under physiologically relevant stress levels. KeraVio including VL irradiation did not cause regression of corneal steepening in this model. Further study is required to evaluate the efficacy of novel treatments for this disorder.

\section{Declarations}

Funding: None. 
Competing interests: The author(s) have made the following disclosure(s):

H.K.: Consultant and equity owner, Tsubota Laboratory Inc. (Tokyo, Japan); Patent, Tsubota Laboratory Inc.

K.T.: Employee and equity owner, Tsubota Laboratory Inc.; Patent, Tsubota Laboratory Inc.

No other disclosures were reported.

Patient consent for publication: Not required.

\section{Research ethics approval: Animals}

All animals were treated according to the Association for Research in Vision and Ophthalmology Statement for the Use of Animals in Ophthalmic and Vision Research.

Provenance and peer review: Not commissioned; externally peer reviewed.

Data availability statement: Data are available upon reasonable request.

Correspondence: Hidenaga Kobashi, MD, PhD, Department of Ophthalmology, Keio University, School of Medicine, Tokyo, Japan. E-mail address: hidenaga_kobashi@keio.jp

\section{References}

1. Rabinowitz YS (1998) Keratoconus Surv Ophthalmol 42:297-319

2. Krachmer JH, Feder RS, Belin MW (1984) Keratoconus and related noninflammatory corneal thinning disorders. Surv Ophthalmol 28(4):293-322

3. Liu YC, Konstantopoulos A, Riau AK, Bhayani R, Lwin NC, Teo EP, Yam GH, Mehta JS (2015) Repeatability and reproducibility of corneal biometric measurements using the Visante Omni and a rabbit experimental model of post-surgical corneal Ectasia. Trans Vis Sci Technol 4(2):16

4. Dawson DG, Grossniklaus HE, McCarey BE, Edelhauser HF (2008) Biomechanical and wound healing characteristics of corneas after excimer laser keratorefractive surgery: is there a difference between advanced surface ablation and sub-Bowman's keratomileusis? J Refract Surg 24(1):S90-S96

5. Hong CW, Sinha-Roy A, Schoenfield L, McMahon JT, Dupps WJ Jr (2012) Collagenase-mediated tissue modeling of corneal ectasia and collagen cross-linking treatments. Invest Ophthalmol Vis Sci 53(4):2321-2327

6. Qiao J, Li H, Tang Y et al (2018) A rabbit model of corneal Ectasia generated by treatment with collagenase type II. BMC Ophthalmol 18(1):94

7. Wang X, Huang Y, Jastaneiah S, Majumdar S, Kang JU, Yiu SC, Stark W, Elisseeff JH (2015) Protective effects of soluble collagen during ultraviolet-a crosslinking on enzyme-mediated corneal Ectatic models. PLoS ONE 10(9):e0136999 
8. Ihalainen A, Salo T, Forsius H, Peltonen L (1986 Feb) Increase in type I and type IV collagenolytic activity in primary cultures of keratoconus cornea. Eur J Clin Invest 16(1):78-84

9. Kobashi H, Torii H, Toda I, Kondo S, Itoi M, Tsubota K (2020 Sep) Clinical outcomes of KeraVio using violet light: emitting glasses and riboflavin drops for corneal ectasia: a pilot study. $\mathrm{Br} \mathrm{J}$ Ophthalmol 5:bjophthalmol-2020

10. Torii H, Ohnuma K, Kurihara T, Tsubota K, Negishi K (2017 Nov) Violet Light Transmission is Related to Myopia Progression in Adult High Myopia. Sci Rep 6;7((1):14523

11. Wollensak G, Spoerl E, Seiler T (2003 Sep) Stress-strain measurements of human and porcine corneas after riboflavin-ultraviolet-A-induced cross-linking. J Cataract Refract Surg 29(9):1780-1785

12. Hammer A, Richoz O, Arba Mosquera S, Tabibian D, Hoogewoud F, Hafezi F (2014) Corneal biomechanical properties at different corneal cross-linking (CXL) irradiances. Invest Ophthalmol Vis Sci. May 2;55(5):2881-4

13. Kobashi H, Yunoki S, Kato N, Shimazaki J, Ide T, Tsubota K (2021) Evaluation of the physiological corneal intrastromal riboflavin concentration and the corneal elastic modulus after violet light irradiation. Translational Vision Science and Technology. in press

\section{Figures}




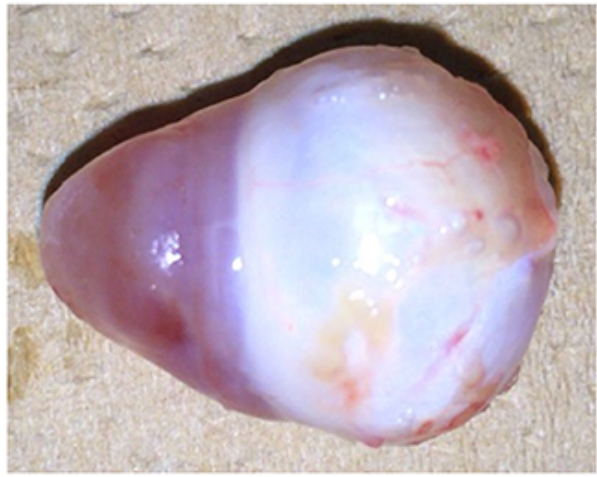

Collagenase group

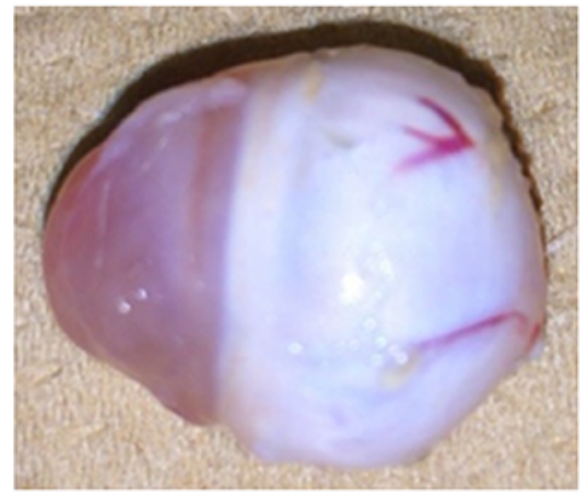

KeraVio with collagenase group

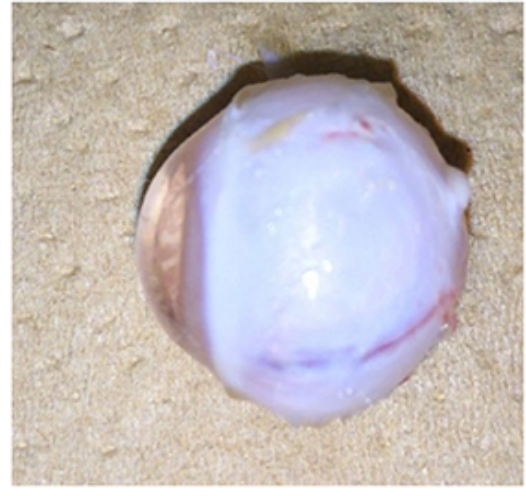

Control group

\section{Figure 1}

Whole eyes demonstrating the axal length in the collagenase, KeraVio with collagenase, and control groups. 